\title{
JOURNEYS IN PHYSICS
}

\section{CHASING SHADOWS, MEASURING MERIDIANS}

\author{
JOSEP BATLLó
}

From the seventeenth century on, problems in physics became the object of careful study. These were mainly related to astronomy and the shape of the Earth, which called for organized scientific expeditions to take measurements in different places. Here we present some of these problems and the solutions adopted at the time.

Keywords: eclipse, Meridian, weather, relativity, travel.

It is easy to understand why naturalists need to travel but the fact that physicists have to undertake expeditions to solve or study certain problems in depth may come as a surprise. You may think: «of course, they must meet with other scientists or visit specially equipped laboratories to perform certain experiments». Certainly this type of travel forms part of the work of any scientist, but that is not the issue dealt with here. Rather, we are talking about journeys undertaken to gather data - otherwise unobtainable - needed to study specific problems. There have been many expeditions, mainly dealing with issues relating to the size and shape of the Earth or other astronomical problems. But, as we will see, some journeys have proved useful to address theoretical problems such as the theory of relativity.

\section{MEASURING THE SOLAR} SYSTEM: TRANSITS OF VENUS IN 1761 AND 1769

Long ago, classical Greek scholars posed the problem of how to calculate the distance from the Earth to the Sun or - put in more modern terms - the value of the Astronomical Unit and the dimensions of the solar system. The answer remained very vague for over 2,000 years. On the one hand, the measuring instruments could not provide accurate data; on the other, the Ptolemaic astronomic system did not make it any easier. But then the Scientific Revolution brought new and more accurate instruments (telescopes and micrometers) and new theories that brought progress.
Johannes Kepler (1571-1630) was the first to calculate the transit of Venus between the Sun and Earth. His prediction, for 1631, had a margin of error of just a few hours. Newtonian mechanics allowed more accurate calculations and he realised that these transits occur only in twos and were a hundred years apart. Therefore, it was not possible to immediately verify Edmund Halley's (1656-1742) proposal that the solar parallax and consequently the distance between the Sun and Earth could be calculated quite accurately from the observations of the transits of Venus (Halley, 1716) as it was necessary to wait for the first pair of transits to occur in 1761 and 1769.

Partly due to inexperience, the 1761 observations turned out to be somewhat unsuccessful. Nonetheless, the Russian physicist Mikhail Lomonosov (1711-1765) was able to conclude there was an atmosphere on Venus. But the errors provided a learning experience and served to make preparations for the 1769 sighting like never before. Institutions in many countries prepared observations each in their own territory, and expeditions to places with the best views (as it is a phenomenon that lasts just a few hours, it is good to find places where it can be seen around noon). Indeed, when the British Royal Society was preparing its expeditions in 1768 , the first news arrived from Samuel Wallis about the island of Tahiti. It seemed like an ideal spot for observation, and so they organized an expedition under the command of James Cook (1728-1779). The observations were made 
at a place still known as Venus Point (Cook and Mohr, 1771).

In addition to observing the transit of Venus, Cook had received orders to find and study the «Terra Australis Incognita», a continent that was supposed to be located in this part of the Earth. Although they did not find it then, they did collect a lot of new geographical and naturalistic data on New Zealand and Australia, virtually unknown at that point (Cook, 1922).

\section{THE SHAPE OF THE EARTH}

According to the gravitational theory put forward by Newton (1642-1727), the Earth could not be spherical, but ellipsoid instead - slightly flattened at the poles -, which is why the measurement of a degree of latitude should not be the same everywhere. However, the measurements taken by the astronomer G. D. Cassini (1625-1712), director of the Paris observatory, pointed

\section{«IN 1769 THE LARGEST EXPEDITION EVER UNDERTAKEN SET OUT TO OBSERVE THE TRANSITS OF VENUS. INSTITUTIONS FROM MANY COUNTRIES PREPARED OBSERVATIONS IN THEIR OWN TERRITORIES AND EXPEDITIONS TO PLACES WHERE THEY WERE MORE FAVOURABLE»}

to a flattened shape at the equator. Given the recognized quality of Cassini's measurements, and both Cassini and Newton's prestige, the French Académie des Sciences undertook an experiment to get to the bottom of the riddle. What they did was to measure the length of a meridian arc in two places where the supposed differences were greatest in order to minimize possible errors. They chose Lapland - as this land is accessible but close to the North Pole - and the Viceroyalty of Peru - then part of the Spanish empire - located on the equator itself. They then organized two expeditions to take measurements in both places simultaneously.

The northbound expedition was led by Pierre-Louis Maupertuis (1698-1759), and left Paris in April 1736 and returned in July 1737 . Not only did they confirm Newton's hypothesis with their measurements, but also took the opportunity to collect ethnographic and naturalistic samples. The southbound expedition to the Viceroyalty of Peru was led by Charles Marie de La

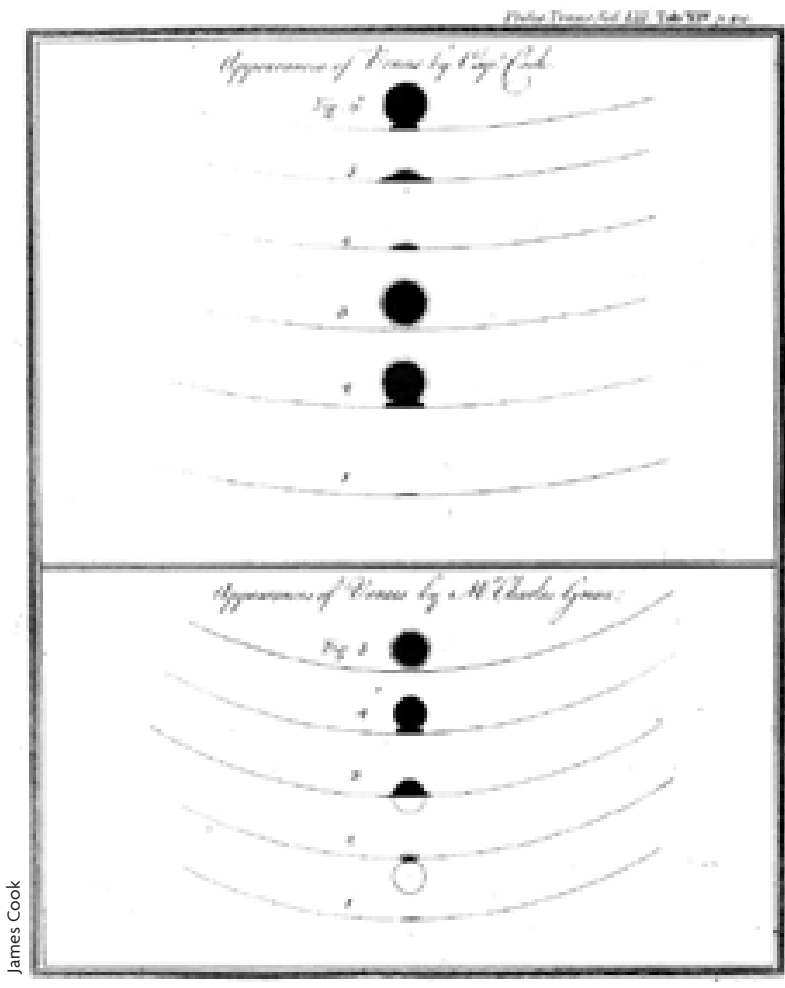

Observations of various contacts during the transit of Venus recorded by James Cook and published in Philosophical Transactions. Note the so-called black-drop effect, which makes it difficult to determine the exact time of contact, which we now know is mainly due the low quality of the optics used.

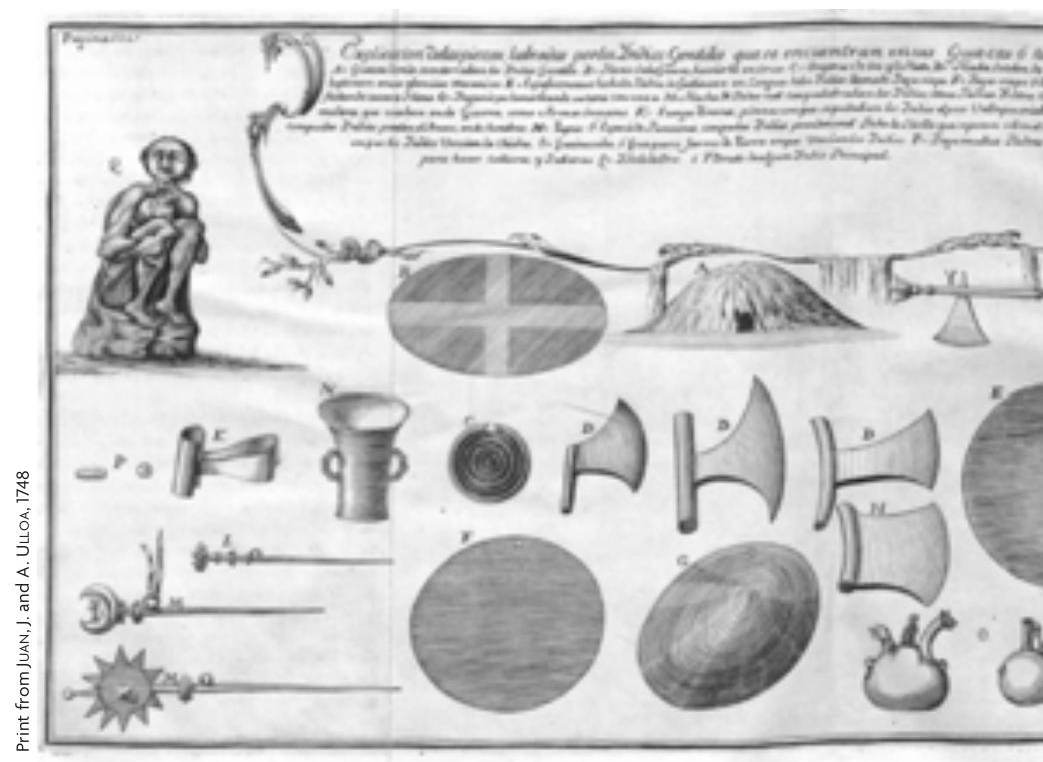

Although the expedition set out to make geodetic observations, it is clear that the observers in Peru (and this goes for any expedition) did not miss the chance to record naturalistic, ethnographic and other interesting data. For instance, amongst the pages describing the work of measuring the meridian, we can find these notes on Inca ruins. On the same expedition, La Condamine wrote a treatise on quinine. 

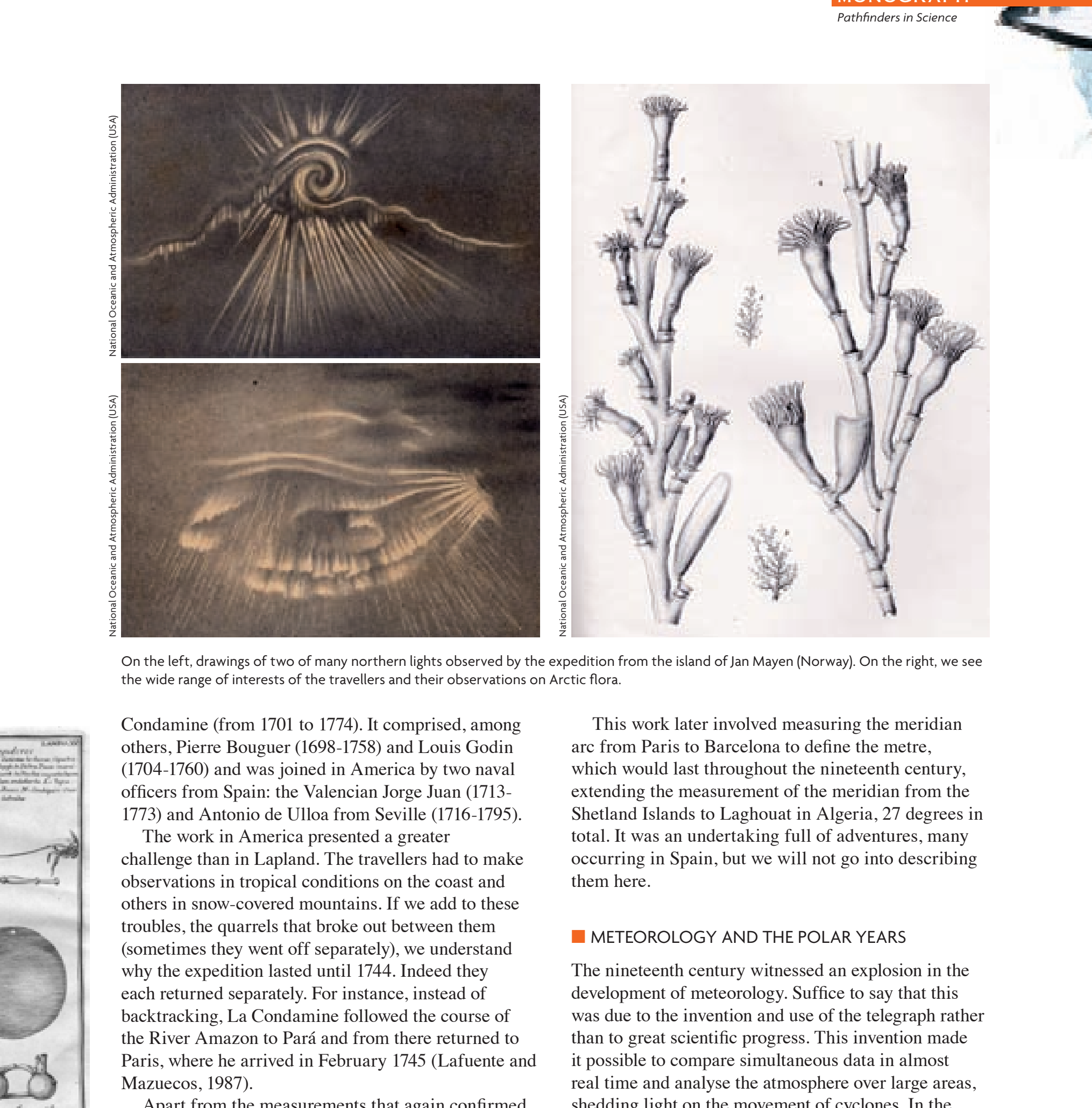

On the left, drawings of two of many northern lights observed by the expedition from the island of Jan Mayen (Norway). On the right, we see the wide range of interests of the travellers and their observations on Arctic flora.

Condamine (from 1701 to 1774). It comprised, among others, Pierre Bouguer (1698-1758) and Louis Godin (1704-1760) and was joined in America by two naval officers from Spain: the Valencian Jorge Juan (17131773) and Antonio de Ulloa from Seville (1716-1795).

The work in America presented a greater challenge than in Lapland. The travellers had to make observations in tropical conditions on the coast and others in snow-covered mountains. If we add to these troubles, the quarrels that broke out between them (sometimes they went off separately), we understand why the expedition lasted until 1744. Indeed they each returned separately. For instance, instead of backtracking, La Condamine followed the course of the River Amazon to Pará and from there returned to Paris, where he arrived in February 1745 (Lafuente and Mazuecos, 1987).

Apart from the measurements that again confirmed Newton's hypothesis, they took many others related to the force of gravity and, for the first time, of the gravitational anomaly detected near the mountains (known as the Bouguer anomaly). They also took many meteorological measurements and witnessed other phenomena and took naturalistic records (Juan and Ulloa, 1748).
This work later involved measuring the meridian arc from Paris to Barcelona to define the metre, which would last throughout the nineteenth century, extending the measurement of the meridian from the Shetland Islands to Laghouat in Algeria, 27 degrees in total. It was an undertaking full of adventures, many occurring in Spain, but we will not go into describing them here.

\section{METEOROLOGY AND THE POLAR YEARS}

The nineteenth century witnessed an explosion in the development of meteorology. Suffice to say that this was due to the invention and use of the telegraph rather than to great scientific progress. This invention made it possible to compare simultaneous data in almost real time and analyse the atmosphere over large areas, shedding light on the movement of cyclones. In the second half of the century, almost all major national meteorological services and data exchange networks were set up and by 1870 , after several attempts, the International Meteorological Organization was established.

At that time, almost all weather stations were in the northern hemisphere, and they soon realised there was 


\section{THE CENTURY OF ECLIPSES ON THE IBERIAN PENINSULA}

A $t$ the turn of the twentieth century, three solar eclipses were visible from the Iberian Peninsula: 18 July 1860; 28 May 1900 and 30 August 1905. Eclipses have always provided the chance to compare observations and forecasts. The motion of the Moon about the Earth, for example, was the first to be described and the last to be carefully calculated (Amengual et al., 2005). The problem lies in the closeness of the moon and the strong influence of the Sun. This is called the three-body problem, which has no analytical solution. So all eclipses are used to test to what extent our estimates are accurate.

\section{«TWO NOVEL ADVANCES STRENGTHENED INTEREST IN ECLIPSES IN THE LATE NINETEENTH AND EARLY TWENTIETH CENTURY: PHOTOGRAPHY AND SPECTROSCOPY»}

But two new issues arose underscoring the particular interest in eclipses in those years. The first was the advent of photography. The year 1842 brought the earliest daguerreotype of an eclipse and from that moment on, those amazing seconds could be «frozen"

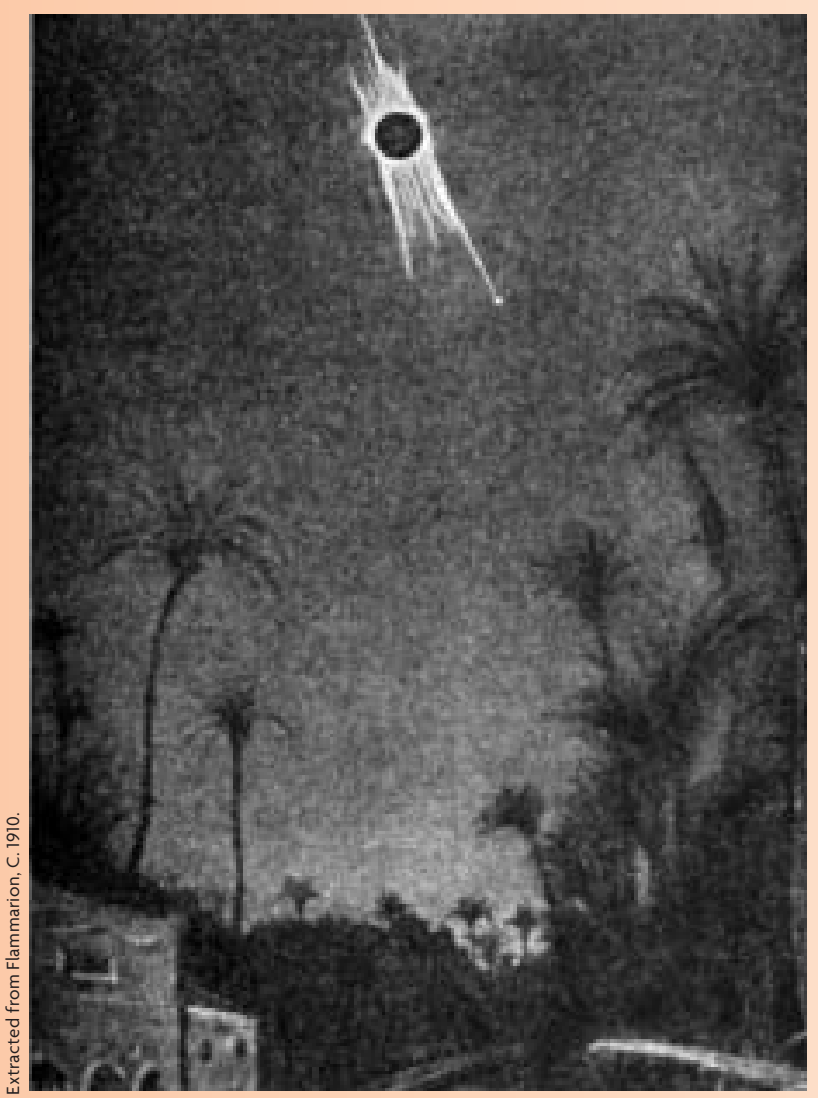

Image of the eclipse in 1900, as seen from Elche (Palmeral de Elche) in Alicante. The sketch was made by T. Moreux's expedition. a strong relationship between major winter depressions affecting Europe and the Polar regions. However, these regions did not have meteorological stations (nor telegraphs that could disseminate their data), therefore it is not surprising that when the Austrian Carl Weyprecht (1838-1881) proposed an expedition to make observations at the Poles, others rallied to the idea immediately. Thus, a number of weather observation expeditions to places with extreme climatic conditions were coordinated and organized internationally rather than nationally, as had been the case before (Batlló, 2008).

This took place between 1882 and 1883 with the participation of twelve countries. To carry out these expeditions, they had to coordinate many aspects, design homogeneous observation methodologies (then not yet fully standardized) and create new instruments (for instance, the commonly used alcohol thermometers froze, and so did the ordinary psychrometers). They defined an entire methodology to observe the northern lights. Indeed, these expeditions were packed with adventures! You can read the original reports of various expeditions, which have recently been digitized ${ }^{1}$. For example, the American expedition to Lady Franklin Bay had to be rescued two years later.

Although not remarkable, the results of the first Polar expedition were useful, and thus on the occasion of the 50th anniversary, the second International Polar Year was organized between 1932 and 1933, encompassing both hemispheres and with better means at its disposal. This was repeated in 1957 and 1958 but was designated as the International Year of Geophysics. In fact, regardless of the epic nature of the first project, the latter was the largest international scientific collaboration ever made up to that time, indeed, we should remember

They can be found at the following website: <http://www.arctic.noaa.gov/aro/ipy-1/index.htm> 


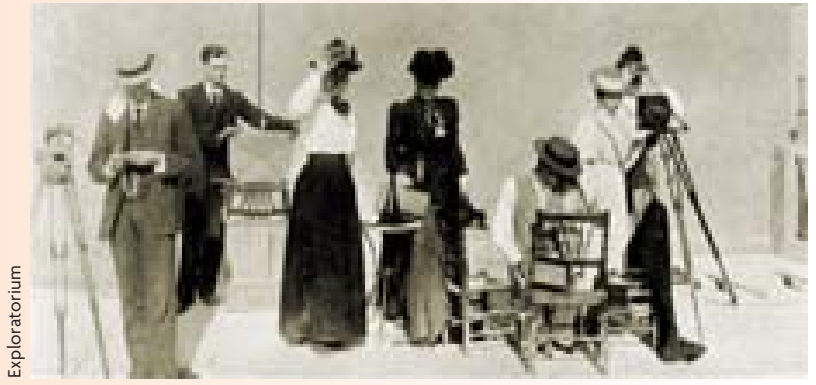

Scientific tourism was a new phenomenon that appeared in the early twentieth century around the time of the eclipses. The picture shows eclipse observers in Elche, 1900.

for later study. The second was spectroscopy. Back in 1840, the first attempts were made to study the solar spectrum. The efforts made to reveal its constitution led to the discovery of helium in 1868, and the false discovery of "coronium» - the chemical element alleged to form the solar corona - in 1869.

Thus, the three full eclipses seen from the peninsula brought domestic or foreign observers flocking as never before (Ruiz-Castell, 2008). All the big names in astronomy of that era were present: Angelo Secchi, Norman Lockyer, Jules Janssen, etc. During the eclipse of 1860, Secchi took his sightings from the Desierto de las Palmas in the province of Castellon, and concluded from his observations that the solar corona was not an effect linked to the moon, as originally thought at the time.

Finally, a new phenomenon appeared around the time of the eclipses in 1900 and 1905: scientific tourism.

that the Soviet Union launched the first artificial satellite, Sputnik, in collaboration with this project.

More recently, a new «Polar Year» was held in 2007-2009, although this event mainly intensified observations and experiments in existing observatories, rather than performing «adventurous» expeditions like the previous ones.

\section{CONFIRMING THE THEORY OF RELATIVITY}

By 1911, Albert Einstein had already postulated that the light from a star would be deflected by passing near the Sun. At that time, it was impossible to observe stars near the Sun (resolved 20 years later, when Bernard Lyot invented the Coronograph in 1931), thus the

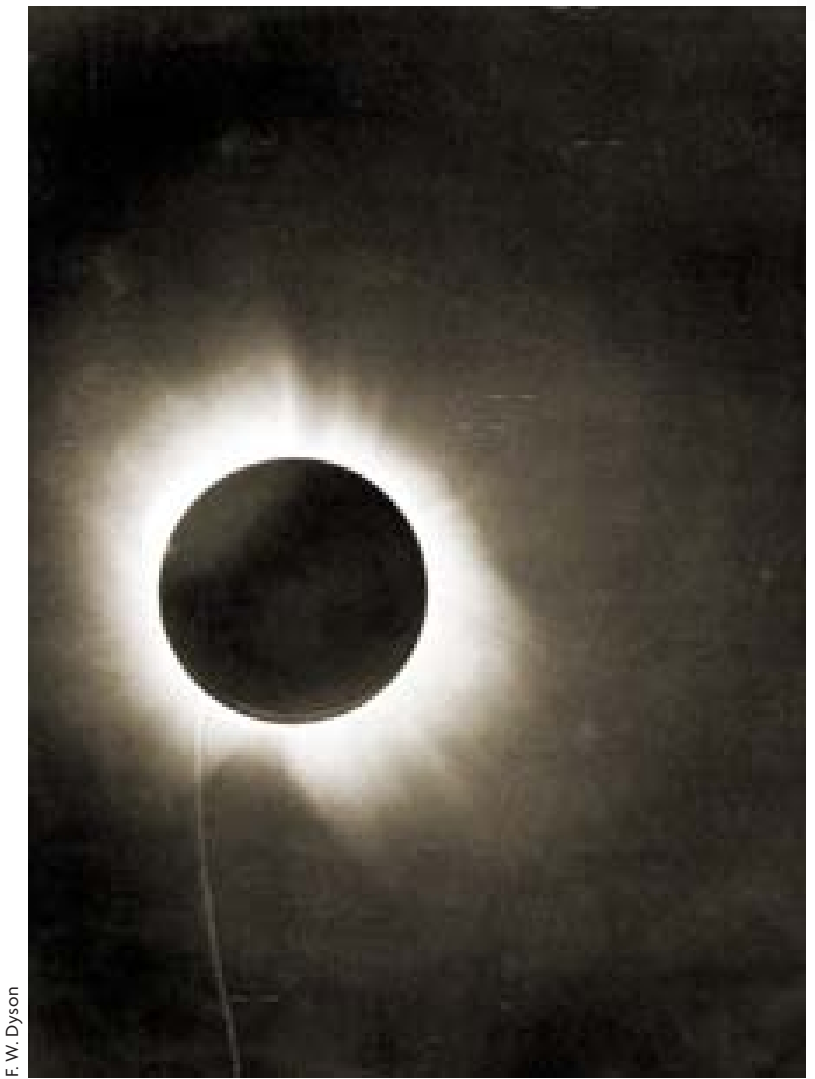

One of the most famous photographs of a solar eclipse, taken by F. W. Dyson in Sobral, Brazil, in 1919. The double horizontal dashes indicate the places corresponding to the stars, object of the study.

only chance to observe and measure the phenomenon was during minute-long eclipses. The first attempt to measure these deviations during the eclipse of 1914 was thwarted by the outbreak of the First World War. The Greenwich expedition was already in Russia, and although the astronomers managed to return to England they were unable to recover their apparatus until 1919.

The first total solar eclipse after the war occurred on 29 May 1919 in the equatorial Atlantic Ocean. The Royal Society prepared two expeditions: one to Sobral, on the coast of Brazil, led by Frank Watson (1868-1939), director of the Greenwich Observatory, and another to the island of Principe, off the West African coast, led by Arthur Eddington (1882-1944), director of the Cambridge Observatory. Unfortunately, bad weather and problematic instruments almost ruined the expeditions. Finally, however, the measurements were taken and confirmed Einstein's postulates (Dyson et al., 1920). 


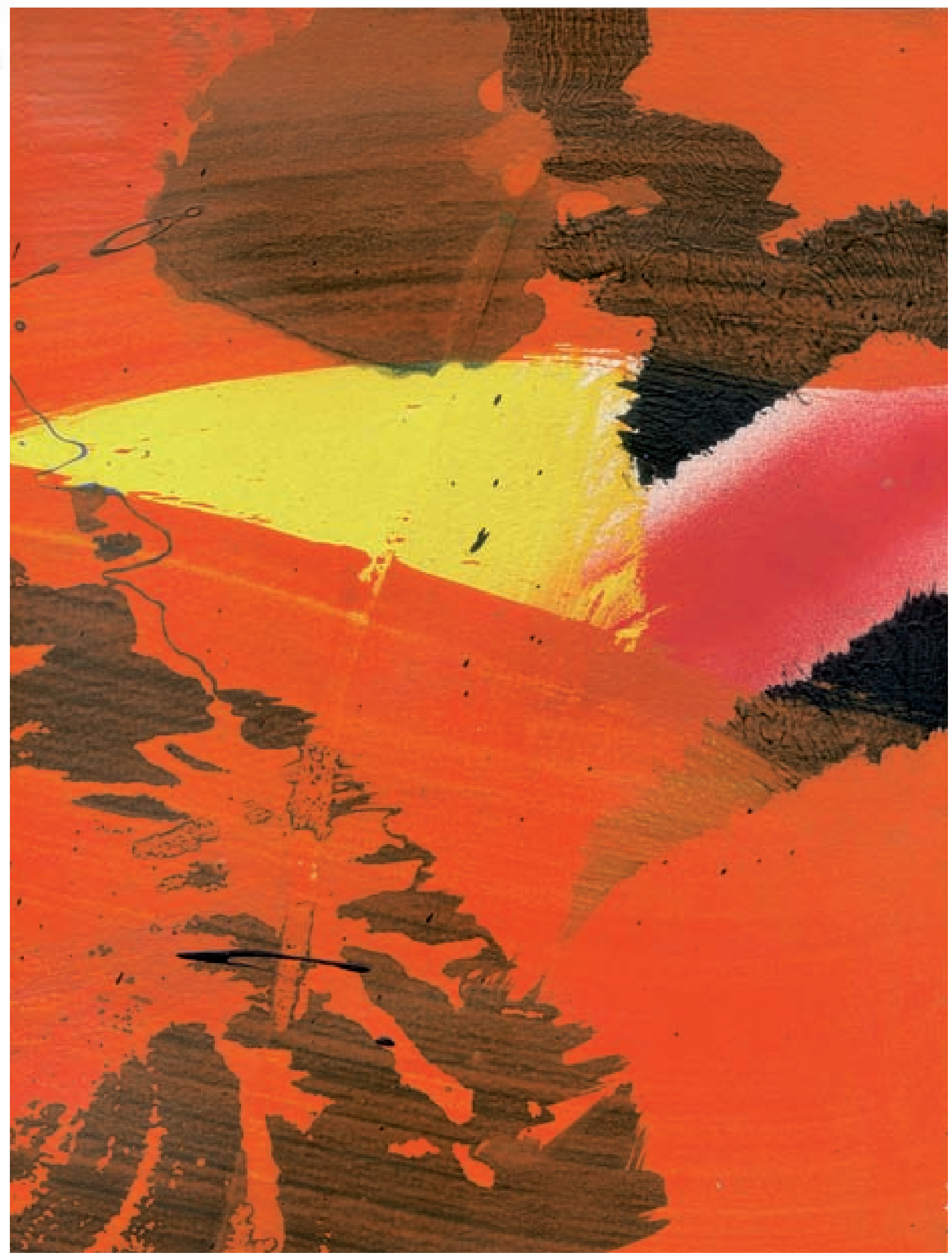

Juan Olivares. Journey to the Centre of the Earth VI, 2013. Acrylic on paper, $21.5 \times 28.5 \mathrm{~cm}$. 


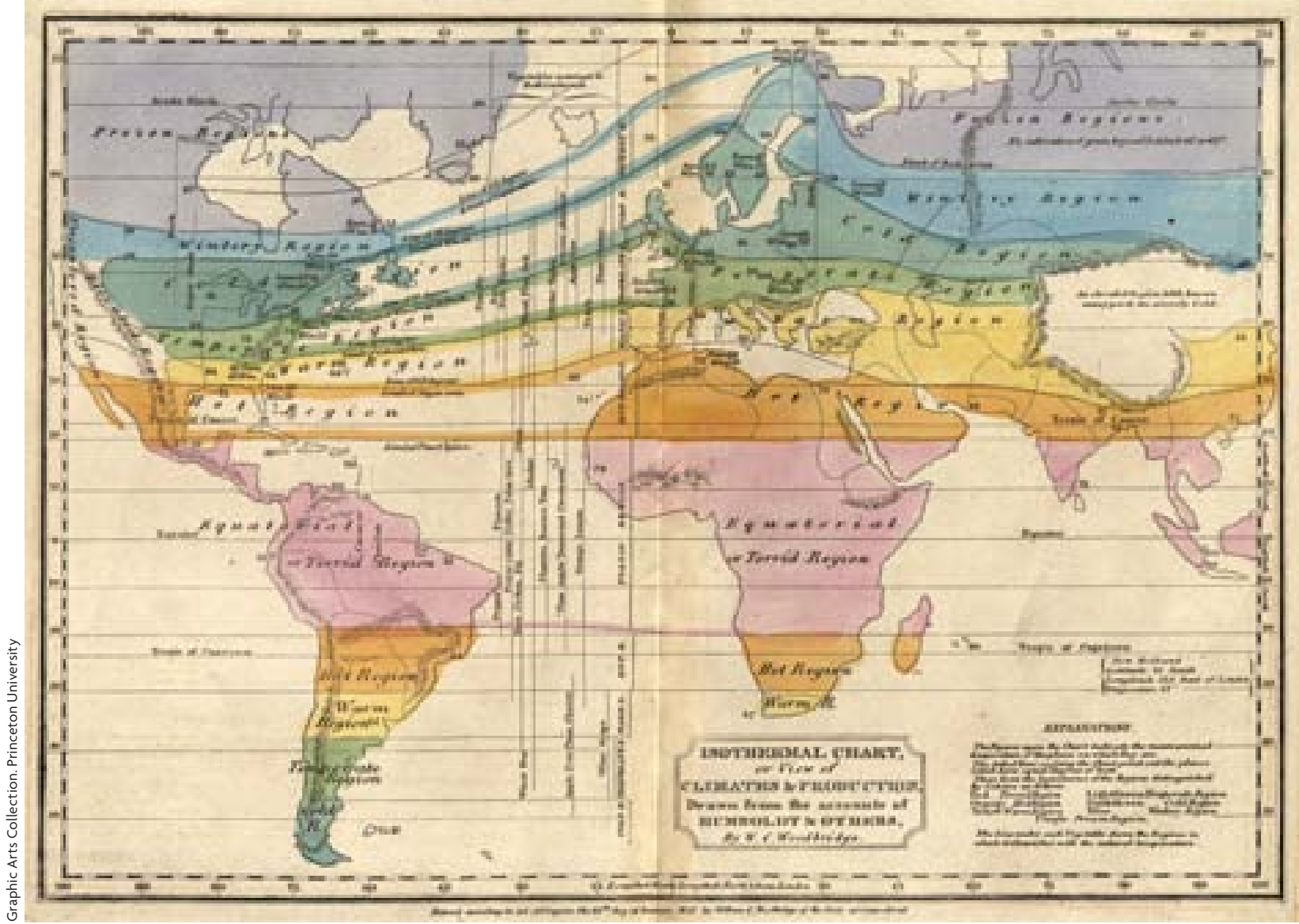

Map of hemispheric temperatures by Alexander von Humboldt. Woodbridge's coloured version. This map could be drawn up when weather stations were not yet common thanks to the information gathered during the travels of many different scholars.

\section{EPILOGUE}

On taking a closer look, we see certain characteristics that are specific to expeditions in physics. The first is that most journeys are coordinated, with various groups travelling to different places. The reason is obvious: one does not need one measurement, but to compare the same measurements from different places.

Also, given the size of the enterprise, it is also common to find they were organized by large scientific institutions rather than the personal interests of particular scientists. However, there are some noteworthy exceptions like, for example, the journey undertaken by Alexander von Humboldt (1769-1859), who took a host of magnetic and meteorological observations, revealing the wide scope of his interests. (-)

\section{REFERENCES}

Amengual, A.; Pons, G. X. and J. March (eds.), 2005. Conferències de les Jornades de Commemoració i Estudi de l'eclipsi total de Sol a la Mallorca de 1905. Societat d'Història Natural de les Balears. Palma.

BAtLló, J., 2008. «Notes on the History of International Polar Years in Catalonia and Spain». Tethys, 5: 47-57. DOI: <10.3369/tethys.2008.5.05>
Соок, J., 1922. James Cook comandante del "Endeavour": relación de su primer viaje alrededor del mundo durante los años 1768, 1769, 1770 y 1771. Calpe. Madrid.

Cook, J. and J. M. Mohr, 1771. «Transitus Veneris \& Mercurii in Eorum Exitu e Disco Solis, 4to Mensis Junii \& 10mo Novembris, 1769, Observatus. Communicated by Capt. James Cook». Philosophical Transactions, 61: 433-436. DOI: <10.1098/rstl.1771.0046>.

Dyson, F. W.; EdDington, A. S. and C. Davidson, 1920. «A Determination of the Deflection of Light by the Sun's Gravitational Field, from Observations Made at the Total Eclipse of May 29, 1919». Philosophical Transactions. Series A, 220: 291-333. DOI: <10.1098/rsta.1920.0009>.

Flammarion, C., 1910. Astronomy for Amateurs. D. Appleton \& Company. New York. Available at: <http://www.gutenberg.org/files/25267/25267-h/25267-h.htm>

Halley, E., 1716. «A New Method of Determining the Parallax of the Sun, or His Distance from the Earth». Philosophical Transactions, 29(338-350): 454-464. DOI: <10.1098/rstl.1714.0056>.

JuAn, J. and A. UlloA, 1748. Relacion histórica del viage a la América Meridional... para medir algunos grados de meridiano terrestre... Antonio Marin. Madrid. Available at the National Spanish Library website: <http://www.bne.es/es/Micrositios/Guias/12Octubre/CienciaExploracion/ JorgeJuan/SeleccionObras/>.

Lafuente, A. and A. Mazuecos, 1987. Los Caballeros del Punto Fijo. Serbal. Barcelona.

Ruiz-Castell, P., 2008. Astronomy and Astrophysics in Spain (1850-1914). Cambridge Scholars Publishing. Newcastle.

Josep Batlló. Researcher at the Dom Luiz Institute. University of Lisbon (Portugal). 